\title{
O MODELO DE “AUTORREGULAÇÃO REGULADA” E A TEORIA DA CAPTURA: OBSTÁCULOS A EFETIVIDADE NO COMBATE A LAVAGEM DE DINHEIRO NO BRASIL $^{1}$
}

\author{
José Carlos de Oliveira ${ }^{2}$ \\ Leonardo Simões Agapito ${ }^{3}$ \\ Matheus de Alencar e Miranda ${ }^{4}$
}

\begin{abstract}
Resumo
O objetivo deste artigo é apontar como o sistema de "autorregulação regulada" no combate à lavagem de dinheiro no Brasil, por meio do incentivo a compliance, termina por levar ao chamado fenômeno da captura das agências reguladoras, impedindo que a prevenção e o combate ao referido delito sejam realmente efetivos. Para tal, foi descrita a estrutura do sistema de prevenção e combate do delito, com especial atenção à autorregulação regulada e aos deveres dos agentes privados de prevenção por meio de compliancee informação aos entes reguladores com finalidade preventiva. Após, foram analisados os dados provenientes desta estrutura particular, apurando-se enfim que os agentes reguladores são dependentes dos regulados, o que torna o sistema ineficaz, gerando a captura dos reguladores. Nas conclusões, algumas causas prováveis e soluções possíveis para o problema são apontadas.
\end{abstract}

Palavras-chave: Lavagem de Dinheiro; Compliance; Autorregulação Regulada; Teoria da Captura; Agências Reguladoras; Prevenção e Combate; Efetividade; Direito Penal; Direito Administrativo.

\section{INTRODUÇÃO}

Cada vez mais exige-se da iniciativa privada obrigações de controle e fiscalização de atos ilícitos. A análise do grau de efetividade dos programas de integridade implantados poderá levar ao amadurecimento do formato brasileiro de responsabilidade dos administradores, adequando-se às exigências legais. Em tempos instáveis como os de hoje, é fundamental que se defina com exatidão a responsabilidade daqueles que podem, de fato, contribuir para que se tenha um ambiente econômico ético e confiável.

\footnotetext{
${ }^{1}$ Trabalho auxiliado por fomento do CNPq, na concessão de Bolsa PIBIC (processo número 135842/2015-8) para o professor José Carlos de Oliveira orientando o então aluno de graduação Matheus de Alencar e Miranda, e pela UNESP, na concessão de Bolsa de Monitoria para o professor José Carlos de Oliveira orientando o então aluno de graduação Leonardo Simões Agapito.

${ }^{2}$ Pós-Doutor em Direito Administrativo pela Universidade de Coimbra. Professor da graduação e do programa de pós-graduação em direito a Faculdade de Ciências Humanas e Sociais da UNESP - Universidade Estadual Paulista "Júlio de Mesquita Filho". Email: oliveira@franca.unesp.br

${ }^{3}$ Mestrando em direito pela Faculdade de Ciências Humanas e Sociais (Unesp-Franca).E-mail: leoagapito@gmail.com

${ }^{4}$ Mestrando em Direito Penal pela UERJ.E-mail: matheus.alencarm@gmail.com
} 
Os reguladores financeiros dos Estados Unidos da América, há tempos, alertam sobre os riscos no México referentes à lavagem de dinheiro ligada ao tráfico de drogas. No ano passado, o México fez mudanças em suas leis de sigilo bancário para permitir que seus bancos compartilhem mais informações sobre seus clientes com bancos no país vizinho. Os riscos para os bancos globais no México não são hipotéticos. O HSBC Holdings PLC e o Citigroup Inc. foram alvos de investigações relacionadas à possível lavagem de dinheiro. Os Estados Unidos da América e o México têm trabalhado em estreita colaboração para ampliar a transparência financeira e isolar transações ilícitas, ligadas ao tráfico de drogas, terrorismo e corrupção 5 .

No Brasil, o paradoxo entre as formas dos mecanismos de enfrentamento da lavagem de dinheiro é nítido. De um lado, alterações na legislação que permitem novos vetores de uma cultura da integridade, as quais estimulam o expurgo das práticas nocivas. De outro lado, o endurecimento das sanções visando a desestimular as práticas nocivas, e no centro do debate, a eficiência do sistema regulador.

O recorte no presente artigo funda-se na abordagem dos obstáculos à efetividade do combate à lavagem de dinheiro e da possível captura do regulador e a efetiva assimetria regulatória que contribuem para a visível ineficiência do sistema no Brasil.

\section{O COMBATE A LAVAGEM DE DINHEIRO NO BRASIL}

O delito de lavagem de dinheiro vem tipificado no art. $1^{\circ}$ da Lei 9.613/98, recentemente alterado pela Lei 12.683/2012 e é tido pela lei como a ocultação ou a dissimulação de "natureza, origem, localização, disposição, movimentação ou propriedade de bens, direitos ou valores provenientes, direta ou indiretamente, de infração penal".

Contudo, a mesma Lei 9.613/98 vem a tentar evitar as supracitadas condutas não só por meio da intervenção penal, mas também com a exigência de contribuição de particulares com o cumprimento de deveres de ordem administrativa que servem para prevenir a lavagem.

De início, a fundamentação para se impor exigências aos particulares advém do fato de que a lavagem de dinheiro não é fácil de ser combatida, não bastando o controle tradicional. Entre as dificuldades principais, alguns motivos são levantados: (a) seu caráter transnacional, (b) sua inserção no informatizado e dinâmico sistema financeiro, (c) o fato de envolver as mais complexas e poderosas organizações criminosas como suas principais praticantes, assim como (d) os crimes com os quais a lavagem se relaciona, considerando que, pela lei, seria qualquer crime ou contravenção, mas tendo em mente que a relação se dá de modo mais acentuado com aqueles crimes e contravenções que movimentam mais dinheiro, no Brasil particularmente o tráfico de entorpecentes, a corrupção, a sonegação fiscal, a evasão de divisas e a exploração de jogos de azar. Por todos estes motivos é que se

${ }^{5}$ Jornal Valor Econômico, 23/24/25 janeiro, 2016. Caderno B-7. 
diz que este é um crime que "reclama para si mais tempo e dinheiro (do ponto de vista da investigação e do procedimento criminal) do que qualquer outro"6. Por isso, o Estado, assumindo sua incapacidade de controlar o problema sozinho, termina por também criar deveres para os particulares visando à prevenção contra a lavagem, neste caso valendo-se do fato de que este é um delito que ocorre em sua grande parte dentro do sistema financeiro e este, por sua vez, é controlado por diversas entidades da Administração Pública que se destinam a regular os serviços públicos bancários e financeiros. Os supracitados deveres estão elencados, basicamente, nos arts. 10 e 11 da Lei 9.613/98. Os obrigados, por sua vez, estão no art. $9^{\circ}$ da mesma lei.

Sendo esta a fundamentação para justificar a imposição aos particulares da participação na prevenção contra a lavagem de dinheiro, resta apontar que isso se dá por meio de duas espécies de deveres administrativos principais: a organização para evitar os delitos e o dever de informar determinadas operações classificadas como suspeitas. Ambos são entendidos como deveres de compliance, no sistema chamado de "autorregulação regulada".

\section{Deveres de compliance e a "autorregulação regulada"}

Compliance é instituto integrado aos quatro pilares da Governança Corporativa (ao lado de fairness, accountabilitye disclosure) e importante ferramenta para a regulamentação interna das empresas. É o setor que cuida da "conformidade no cumprimento de normas reguladoras, expressas nos estatutos sociais, nos regimentos internos e nas instituições legais do país"7. Estar em compliance é manter-se em conformidade com as leis e padrões éticos, agindo de maneira preventiva, tentando antecipar condutas reprováveis e criando mecanismos para evitar ações que possam deixar a empresa em desconformidade com o conjunto de normas e preceitos éticos reguladores de sua atividade.

Na década de 1990, compliance deixou de ser um princípio norteador da atividade empresarial e passou a ter relevância concreta para o ordenamento jurídico, vez que o Estado legislou no sentido de exigir sua implantação por parte das empresas em um sistema de corregulação na Lei 9.613/98. Conforme exposto, duas são as espécies dos principais deveres chamados deveres de compliance ${ }^{8}$ : (1) a organização para evitar os delitos e (2) o dever de informar determinadas operações classificadas como suspeitas.

Para (1) a organização para evitar os delitos, observa-se a princípio que "as estratégias dos diversos países

\footnotetext{
${ }^{6}$ DAVIN, João. O branqueamento de capitais - breves notas (o caso português). In: OLIVEIRA, William Terra de; LEITE NETO, Pedro Ferreira; ESSADO, Tiago Cintra; SAAD-DINIZ, Eduardo (coord.). Direito penal econômico: estudos em homenagem aos 75 anos do professor Klaus Tiedemann. São Paulo, SP: LiberArts, 2013.p. 212.

${ }^{7}$ ROSSETTI, José Paschoal; ANDRADE, Adriana. Governança corporativa. Fundamentos, desenvolvimento e tendências. 6. ed. São Paulo: Atlas, 2012, p.141.
} 
de combate à lavagem de dinheiro têm como elemento comum o reconhecimento da incapacidade do Poder Público para prevenir ou investigar tal delito sem a colaboração das instituições privadas que atuam nos setores

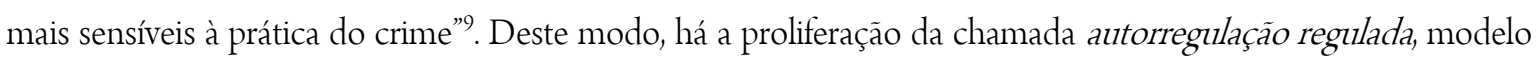
em que algumas premissas são dadas pelo Estado, "cabendo às empresas buscar códigos de conduta internos para melhor se adequarem à nova realidade" ${ }^{\prime 0}$. Aqui se inserem os programas de compliance, programas de prevenção internos das empresas.

Para (2) o dever de informar determinadas operações classificadas como suspeitas, no mesmo intuito de cooperação, a lei caracteriza como gatekeepers ou torres de vigia determinadas entidades ou pessoas que operam em campos sensíveis à lavagem de dinheiro, que exerçam atividades em setores comumente usados pelos agentes que mascaram bens de origem ilícita como bancos, corretoras de valores, de imóveis, contadores, etc., impondolhes determinados deveres. Essa posição privilegiada faz com que estes personagens não só tenham a obrigação de (a) não colaborar com a prática de atos ilícitos, mas também a de (b) contribuir nas atividades de inteligência e vigilância do poder público, informando-o de quaisquer atos praticados sob seu escopo de atuação que tenham aparência de lavagem de dinheiro. ${ }^{11}$

Cabe ainda ressaltar que a alteração da Lei 9.613/98 pela Lei 12.683/2012 veio a fortalecer a regulação administrativa de setores sensíveis à lavagem de dinheiro na medida em que "a nova lei (Lei 12.683/2012) trouxe inovações importantes, como a ampliação do âmbito de abrangência típico e a inclusão de novas obrigações administrativas - aplicadas a um novo e mais amplo rol de entidades e pessoas" ${ }^{12}$. Deste modo, é possível concluir que as mudanças após a reforma foram bastante relevantes, com a ampliação dos deveres de compliance nos dois sentidos possíveis: (a) ampliando os agentes obrigados do art. 9 da Lei; e (b) aumentando as próprias regras e exigências, ou seja, os próprios deveres de compliance dos arts. 10 e 11.

Importante, neste sentido, é ressaltar que, no mundo inteiro, esse tipo de sistema de corregulação prevê que, (I) por parte das empresas, que elas se regulamentem de modo a prevenir internamente os atos indesejados (no caso da Lei 9.613/98, a lavagem de dinheiro), tendo como ato essencial o fornecimento de certas informações aos agentes reguladores; enquanto, (II) por parte do Estado, além de receber e processar as

\footnotetext{
${ }^{8}$ Utilizando o termo "deveres de compliance" em referência aos deveres dos arts. 10 e 11 da Lei 9.613/98, ver: SAAVEDRA, Giovanni A. Reflexões iniciais sobre o controle penal dos deveres de compliance. In: Boletim IBCCRIM. São Paulo: IBCCRIM, ano 19, n. 226, p. 13-14, set., 2011.

9 BADARÓ, Gustavo Henrique; BOTTINI, Pierpaolo Cruz. Lavagem de Dinheiro: aspectos penais e processuais penais: comentarios à Lei 9.613 com as alterações da Lei 12.683/2012. Prefácio de Maria Thereza Rocha de Assis Moura. São Paulo: Editora Revista dos Tribunais, 2013.p. 34-35.

${ }^{10}$ SCAFF, Fernando Facury e SILVEIRA, Renato de Mello Jorge. Lei Anticorrupção é substancialmente de caráter penal. ISSN 1809-2829. CONJUR, 2014. Disponível em: <http://www.conjur.com.br/2014-fev-05/renato-silveira-fernando-scaff-leianticorrupcao-carater-penal> (com acesso em 10-06-2014).

${ }^{11}$ BADARÓ, Gustavo Henrique; BOTTINI, Pierpaolo Cruz. Op. cit., p. 35.

${ }^{12}$ Ibid., p. 25.
} 
informações no sentido de buscar evitar a infração das normas (aqui a lavagem de ativos), ele terá de conceber vantagens às empresas que cumpram os procedimentos e, ainda assim, sejam surpreendidas com a ocorrência de infrações em seu interior e, por outro lado, sancionar (aqui administrativamente) as empresas que não cumpram os procedimentos da lei, em um sistema chamado "carrot and stick"s.

Ocorre que, no Brasil, os agentes que cumprirão a função do Estado no sistema "carrot and stick" da Lei Antilavagem são exatamente as agências reguladoras das empresas obrigadas a informar. Neste cenário, dois órgãos irão destacar-se: (1) o Banco Central do Brasil (BACEN), porque é o regulador dos Bancos; e (2) o Conselho de Controle de Atividades Financeiras (COAF), porque (i) é a Unidade de Inteligência Financeira (UIF) brasileira, responsável por receber, armazenar e sistematizar informações, elaborar Relatórios de Inteligência Financeira, e contribuir para o combate à lavagem de dinheiro com base em planejamento estratégico, de ações de inteligência e de gestão de dados, e (ii) porque é o órgão responsável pela regulação e pelo processamento de todas as pessoas obrigadas que não tenham agência regulatória própria.

\section{O papel dos entes reguladores no combate à lavagem}

Inicialmente, o conceito de regulação econômica tem em vista dois objetivos bastante definidos, a saber: a eficiência do mercado e a proteção do investidor. Um Estado que garante a livre iniciativa, por meio da regulação, deve aliar interesses próprios, dos agentes econômicos e dos consumidores, garantindo o respeito às estruturas de mercado, incentivando a concorrência e impedindo abusos de poder econômico ${ }^{14}$. Compreendendo a atual configuração do mercado e a necessidade de intervenção, adota-se o modelo de autorregulação regulada, de modo que às agências reguladoras resta o papel de analisar as informações prestadas e de aplicar as sanções ou medidas cabíveis. ${ }^{15}$

No Brasil, a regulação do sistema financeiro dá-se por diferentes órgãos vinculados ao Ministério da Fazenda. Toda a estrutura do Ministério é atualmente definida pelo Decreto n.7.482/11. No artigo 20 deste decreto, estão definidas todas as entidades vinculadas ao Ministério da Fazenda, divididas entre: I) órgãos de assistência direta e imediata ao Ministro de Estado; II) órgãos específicos singulares; III) órgãos colegiados (dentre os quais, destacam-se para este estudo o Conselho Monetário Nacional e o Conselho de Controle de Atividades Financeiras); IV) entidades vinculadas (divididas entre autarquias, como o Banco Central e a

\footnotetext{
${ }^{13}$ Sobre o termo e este sistema regulatório, LAUFER, William S. Corporate Liability, Risk Shifting and the Paradox of Compliance. In: Vanderbilt Law Rewiew, vol.:52, p. 1.343-1.420, 1999.

${ }^{14}$ Ver: SEIXAS, "A regulação do mercado de capitais no âmbito internacional", p.100 e ss. Com base em YAZBEK, o autor ainda define a regulação como a atividade de criar normas, implementar atos administrativos e fiscalizar o cumprimento destas valendose, caso necessário, de sanções.

${ }^{15}$ Sobre a evolução do modelo de regulação: SAAD-DINIZ, "O sentido normativo dos programas de Compliance na AP n.470/MG". Revista dos Tribunais, 2012, p.167 e ss.
} 
Comissão de Valores Mobiliários; as empresas públicas, como a Casa da Moeda e a Caixa Econômica Federal; e as sociedades de economia mista, como o Banco do Brasil e o Banco da Amazônia).

Aliados a estes estão, ainda, o Departamento de Recuperação de Ativos e Cooperação Jurídica Internacional (DRCI) e o Conselho Administrativo de Defesa Econômica (CADE), ambos vinculados ao Ministério da Justiça, que auxiliam na prevenção e na apuração de delitos econômicos ou medidas anticoncorrenciais.

\section{$\underline{B A C E N}$}

O Banco Central do Brasil é uma autarquia do Ministério da Fazenda, responsável por determinar as regulamentações da atividade financeira no país. Para o presente trabalho, as normativas relevantes ao tema serão divididas em dois blocos, a saber: (a) quanto aos deveres de informar; (b) quanto aos deveres de conformidade na atuação.

Regulamentação das informações prestadas aos órgãos de controle

O Banco Central tem suas cartas circulares e nas resoluções administrativas pautadas pelas "40 Recomendações do GAFI", que se encontram disponíveis em três versões na plataforma digital do órgão ${ }^{16}$. Dentre as recomendações relevantes ao tópico, algumas se destacam. A recomendação n.2, que dispõe acerca da cooperação e da coordenação das informações entre países, determina a necessidade de se unificarem as informações financeiras e a criação de mecanismos eficazes que permitam o compartilhamento rápido destas entre os países. Com relação ao sigilo profissional, dispõe a recomendação n.9 que as normas de sigilo não podem configurar óbice à aplicação das recomendações do Grupo de Ação Financeira Internacional (GAFI).

A recomendação n.10 determina que as instituições financeiras não podem manter contas anônimas (know your client policy), devendo as informações exigidas serem mais detalhadas à medida que os valores e a complexidade das movimentações cresçam. Os dados devem ser conferidos sob pena de interrupção da transação. As entidades sem personalidade jurídica, em particular, devem oferecer informações sobre seus fundadores, administradores e apresentar suas fontes de recursos (recomendação n.25). Não apenas tais obrigações deveriam ser impostas aos novos clientes, mas aos já existentes. $\mathrm{O}$ banco de dados de cada instituição deve armazenar documentos suficientes para reconstituir todas as transações financeiras realizadas no espaço mínimo de cinco anos (recomendação n.11). Caso uma dessas operações se mostre suspeita, seja pelo valor, seja pela operação em si, as autoridades competentes devem ser informadas (recomendação n.20). 
Diante destas exigências internacionais, o Banco Central emitiu, em 2009, a Carta Circular n. 3.461, revisada pela Circular n.3.654 em 2013. Dentre as principais exigências, destacam-se: (I) em seu art.2º, estão definidas as informações mínimas necessárias para que um cliente seja aceito (pessoa física ou jurídica), devendo ainda os antigos clientes terem seus cadastros atualizados, tendo este rol de informações sido alterado pela carta circular n.3.654, de 2013; (II) em seu art.60, exige-se o registro de todos os serviços financeiros prestados suficientes para análise posterior da compatibilidade entre a movimentação de recursos e a atividade econômica e a capacidade financeira do cliente, da origem dos recursos movimentados e dos beneficiários finais das movimentações; (III) ainda no art.6 ${ }^{\circ}$, exige-se o registro de toda movimentação que supere o valor de R\$10.000,00 (dez mil reais) ou que gere a suspeita de ser artificio de engano; (IV) todos os dados devem ser armazenados por, no mínimo, cinco anos, exceto algumas movimentações com cheques, que devem ser armazenados por, no mínimo, dez anos (art.11); (V) toda movimentação acima de $\$$ \$100.000,00 (cem mil reais) ou, ainda que inferior, mas que pareça suspeita, deve ser comunicada ao COAFaté, no máximo, o próximo dia útil (art.12). Para tanto, os procedimentos, os instrumentos de comunicação e as situações exemplificativas devem ser amplamente divulgados pelo Banco Central (art.19).

Semelhantemente à circular referida, a Resolução n. 4.331, de 2014, em seu art.9\%, determina para as operações no âmbito do SML os deveres de: I - identificar o cliente (remetente ou destinatário, conforme o caso); II - obter suporte documental que comprove a operação. Este último fica dispensado caso o valor da operação seja igual ou inferior a US\$3.000,00 (três mil dólares dos Estados Unidos).

Regulamentação dos deveres de conformidade na atuação

Seguindo a disposição da análise anterior, acerca da conformidade aos padrões de segurança do GAFI, recomenda-se que cada país, ao implementar um modelo de atuação, avalie os riscos e as principais fontes de risco sistêmico a que suas instituições estão submetidas, adaptando programas que coíbam o financiamento do terrorismo e a lavagem de dinheiro coerentes. A mesma análise é exigida das instituições e dos profissionais para que operem no sistema financeiro.

À luz disto, a Circular n. 3.461, em seu art.1 ${ }^{\circ}, \$ 1^{\circ}$, exige políticas claras de organização interna e de análise de riscos, a saber: I) especificar, em documento interno, as responsabilidades dos integrantes de cada nível hierárquico da instituição; II) contemplar a coleta e o registro de informações tempestivas sobre clientes, que permitam a identificação dos riscos de ocorrência da prática dos mencionados crimes; III) definir os critérios e os procedimentos para seleção, treinamento e acompanhamento da situação econômico-financeira dos empregados

\footnotetext{
${ }^{16}$ Disponível em <http://www.coaf.fazenda.gov.br/links-externos/As\%20Recomendacoes\%20GAFI.pdf> (com acesso em 05-092015).
} 
da instituição; IV) incluir a análise prévia de novos produtos e serviços, sob a ótica da prevenção dos mencionados crimes; V) ser aprovada pelo conselho de administração ou, em sua ausência, pela diretoria da instituição; VI) receber ampla divulgação interna.

De acordo com o $\$ 2^{\circ}$, tais procedimentos teriam de aliar-se a medidas expressas que permitam: I) confirmar as informações cadastrais dos clientes e identificar os beneficiários finais das operações; II) possibilitar a caracterização ou não de clientes como pessoas politicamente expostas ${ }^{17}$. O $\$ 4^{\circ}$ deixa claro o intuito de viabilizar a cooperação internacional e de garantir transparência na forma como a instituição conduz seus investimentos.

Quanto ao compliance officer ${ }^{18}$, o art. 18 determina que as instituições financeiras indiquem ao Banco Central do Brasil o diretor responsável pela implementação e pelo cumprimento das medidas estabelecidas nesta circular, bem como pelas comunicações, ainda que este desempenhe outras funções na instituição, exceto a relativa à administração de recursos de terceiros.

Quanto a estes tópicos, a Circular n. 3.654 alterou a redação do caput do art.1º, criando a exigência de que os programas de prevenção sejam compatíveis com o "porte e o volume de operações" da instituição, enquanto o art.10 ressalta a necessidade de "monitoramento contínuo reforçado, mediante a adoção de procedimentos mais rigorosos para a apuração de situações suspeitas".

Com relação ao sistema de pagamento em moeda local (SML), a Resolução n. 4.331 exige o Banco Central especial e prévia autorização para operarem em território nacional, sendo requisito para sua concessão a conformidade aos padrões técnicos de "comunicação eletrônica de dados no âmbito do Sistema Financeiro Nacional (SFN) estabelecidos pelo BCB, aplicáveis ao SML” (art.4º \$ \$2º.

Sanções aplicadas pelo Banco Central

Conforme restou claro, as recomendações do GAFI estabelecem padrões a serem impostos regionalmente. Porém, há uma grande preocupação ainda com a forma como é conduzida a supervisão pelos órgãos oficiais, sendo as mais relevantes: (a) especial atenção aos bancos de fachada, submetendo-os à análise prévia e ao acompanhamento contínuo (recomendação n.26); (b) condições ideais para inspecionar, exigir informações relevantes e cumprimento de obrigações, além de poderes para imposição de sanções disciplinares e financeiras (cancelar, restringir ou suspender a autorização para atuar), caso desrespeitada (recomendação n.27); (c) centralização das informações e da análise de denúncias (recomendação n.29); (d) capacidade para congelar e

\footnotetext{
${ }^{17}$ De acordo com a Circular n.3461 do Banco Central, são "Pessoas Expostas Politicamente" (PEP) aqueles que exercem ou exerceram cargo público ou função relevante, no Brasil ou no exterior, nos últimos cinco anos. Os cargos e funções estão listados, para uma interpretação restritiva, nesta mesma circular.

${ }_{18}$ Compliance officer é o indivíduo que assume a responsabilidade pelo programa de Compliance de uma determinada corporação.
} 
apreender bens utilizados ou provenientes de atividade criminosa (recomendação n.30); (e) poderes coercitivos para recolher documentos, depoimentos e demais provas necessárias para a investigação (recomendação n.31); (f) realização de estudos estatísticos sobre matérias relevantes para a eficiência do sistema (recomendação n.33) ${ }^{19}$; (g) retorno de toda comunicação oferecida pela instituição, informando as providências tomadas e sugerindo medidas a serem aplicadas e diretrizes de atuação segura, de forma a efetivar a "autorregulação regulada" (recomendação n.34); (h) garantia de que o sistema jurídico tenha sanções proporcionais e dissuasivas de natureza civil, administrativa e criminal aplicáveis a pessoas singulares ou coletivas que descumprirem as recomendações (recomendação n.35).

Pela mesma ordem, a Resolução n.4.282, de 2013, estabeleceu as diretrizes da regulamentação do sistema de pagamentos brasileiro, sendo seus princípios, dentre outros a confiabilidade, qualidade e segurança dos serviços de pagamento e inclusão financeira, observados os padrões exigidos.

Para o devido cumprimento de todas as funções assumidas, o Banco Central criou um "Manual de Supervisão" para instruir seus agentes. A supervisão, de acordo com o manual, deve observar: (a) os riscos assumidos e a capacidade de gerenciamento dentro de limites regulamentares e prudenciais; (b) o cumprimento das normas específicas e a conformidade aos padrões legais e regulamentares de atuação; (c) a divulgação de informações pelas instituições supervisionadas de governança corporativa nos aspectos de transparência e equidade no relacionamento com os participantes do mercado; (d) a realização da supervisão particular de conduta. $^{20}$

A seção n.20 define o acompanhamento das instituições como a supervisão das atividades e do planejamento desenvolvido, considerando as características, o porte, o perfil de risco e a complexidade, observando a solidez da organização, as alterações da estrutura patrimonial e o perfil de riscos. Cabe aos supervisores medir a qualidade da gestão, o cumprimento de normas e a confiabilidade das informações contábeis em cada nível hierárquico. ${ }^{21}$

Por fim, com relação às sanções, a Circular n. 3.461 teve sua redação também alterada pela Circular n. 3.654, de 2013, atribuindo ao Banco Central a competência para aplicar sanções previstas na Lei n. 4.595/64, inclusive em casos de violação aos deveres impostos pela Lei n. 9.613/98, tanto às instituições quanto a seus administradores que deixarem de cumprir as obrigações estabelecidas.

Todas as modalidades são aplicáveis às pessoas físicas e jurídicas que atuem no sistema financeiro, com exceção à proibição para atuar (com limite máximo de vinte anos), aplicável às empresas de auditoria, auditores

\footnotetext{
${ }^{19} \mathrm{O}$ Banco Central desenvolve alguns estudos e disponibiliza em sua plataforma digital. Ver: <http://www.bcb.gov.br/?estatsfn> (com acesso em 17-05-2015).

20 Manual de Supervisão, disponível em: < https://www3.bcb.gov.br /gmn/visualizacao/listar Documentos ManualPublico.do?method=listarDocumentosManualPublico\&idManual=1 > (com acesso em 23-09-2015), p.39.
} 
independentes e auditores responsáveis pela auditoria de instituições autorizadas a funcionar pelo Banco Central (de acordo com a Lei n. 6.385/76, art.26). A pena de multa, a depender da infração - sendo exemplo a infração à lei de lavagem -, pode chegar a $\mathrm{R} \$ 2.000 .000,00$ (dois milhões de reais). A inabilitação, em caso de violação aos deveres impostos pela Lei n. 9.613/98, pode chegar a dez anos. Ainda é possível que as penas sejam aplicadas cumulativamente.

\section{$\underline{\mathrm{COAF}}$}

O COAF é órgão colegiado do Ministério da Fazenda ${ }^{22}$, cuja configuração foi apresentada anteriormente. São setores regulados pelo COAF: (a) o comércio de bens de luxo ou de alto valor; (b) administradoras de cartões de crédito que não sejam instituições financeiras e administradoras de cartões de credenciamento; (c) empresas de factoring e securitização de ativos e títulos mobiliários; (d) comércio de joias, pedras e metais preciosos; (e) comércio de objetos de arte e antiguidade; (f) pessoas jurídicas não financeiras que realizam serviços de transferência nacional ou internacional de numerário; (g) empresas de assessoria, consultoria, auditoria, aconselhamento ou assistência ${ }^{23}$. Outros órgãos reguladores, como o CVM e BACEN, ainda enviam toda operação suspeita de lavagem ou outro ilícito para análise do COAF. Dessa forma, entendeu a administração pública que estes seriam os setores considerados mais frágeis, tanto pela atividade, quanto pela falta de regulação específica, para operações de lavagem de dinheiro.

Cumprindo a recomendação n. 29 do GAFI, o COAF atua como Unidade de Inteligência Financeira, centralizando e avaliando informações e denúncias. Pela Lei n. 9.613/98, são suas funções também disciplinar atividades econômicas e aplicar sanções aos administradores e às pessoas jurídicas que deixem de cumprir as obrigações nela previstas. Cumulativamente ou não, as sanções são as mesmas aplicáveis pelo Banco Central. ${ }^{24}$

Por atuar como órgão regulador de diferentes setores específicos, é função do COAF detalhar as obrigações impostas pelos arts. 10 e 11 da Lei no 9.613/98 2 . Tais resoluções esclarecem os procedimentos de prevenção de forma particular a cada um dos setores, sendo seu dever observar a efetividade na implementação. ${ }^{26}$

A revisão, em 2012, da Lei de Lavagem, foi entendida como um "fortalecimento da rede de prevenção à

\footnotetext{
${ }^{21}$ Ibid., p.14.

${ }^{22}$ Ver entrevista com Adrienne Senna Jobim, primeira presidente do COAF (1998-2002), em “Caso \& Caso: 1ª coletânea de casos brasileiros de lavagem de dinheiro", p.8.

${ }^{23}$ Deve-se observar que o COAF age como agente regulador destes setores de forma estratégica. Embora no ambiente das instituições financeiras haja riscos, são nos referidos setores que ocorre mais facilmente o último processo da lavagem, de reinserção do capital na economia. Com tal exercício, a apuração de denúncias é facilitada.

${ }^{24}$ Ver: <https://coaf.fazenda.gov.br/menu/sendo-regulado/processo-administrativo> (com acesso em 23-09-2015).

${ }^{25}$ Ver entrevista com Adrienne Senna Jobim, primeira presidente do COAF (1998-2002), em "Caso \& Caso: 1ª coletânea de casos brasileiros de lavagem de dinheiro", p.11.

${ }^{26}$ Ver: <http://www.coaf.fazenda.gov.br/menu/pld-ft/sobre-a-lavagem-de-dinheiro> (com acesso em 23-09-2015).
} 
lavagem de dinheiro e ao financiamento do terrorismo", tornando "mais coesos os deveres das pessoas obrigadas e os instrumentos dos órgãos supervisores" ${ }^{\prime 27}$. A partir destas alterações, todas as instituições e os agentes que atuem em um desses setores deve ter prévio cadastro autorizado no COAF (seguindo as mesmas recomendações do GAFI). Ainda em complemento às obrigações de manutenção de cadastros de clientes e aos registros de operações e à comunicação de operações suspeitas ao COAF, exige-se atualmente a implementação de políticas de transparência e de controles internos ${ }^{28}$.

As comunicações recebidas pelo SISCOAF $^{29}$ recebem uma análise eletrônica pré-programada e são distribuídas individualmente aos analistas técnicos. ${ }^{30}$ Toda comunicação recebida e todo o processo por que esta passa são registrados e armazenados no mesmo software, de forma que o banco de dados tem um volume crescente e construtivo ${ }^{31}$, utilizando as rotinas trabalhadas como subsídio para a resolução de comunicações subsequentes $^{32}$. A central de gerenciamento de risco e de prioridades (CGRP) apura cada comunicação e abre arquivos para aprofundamento de cada caso. Os casos ainda são hierarquizados de acordo com a amplitude do risco pela mesma central. ${ }^{33}$

Encerradas as análises, registra-se o relatório de inteligência financeira (RIF). O RIF pode ainda originarse: (a) de ofício, a partir de uma atuação espontânea do COAF; (b) por um intercâmbio de informação (uma denúncia que não se originou por um dos órgãos fiscalizados, mas por outro órgão regulatório nacional); (c) pela solicitação de uma autoridade estrangeira ou por outra unidade de inteligência financeira. ${ }^{34}$

Com base no art.15, da Lei de Lavagem, caso as análises concluam pela existência fundada de indícios de lavagem, deve o COAF encaminhar o RIF, bem como todas as provas colhidas, às autoridades competentes. Até seu encaminhamento ao órgão responsável, o conteúdo do RIF é sigiloso, nos termos do referida LC n.105/01.

\footnotetext{
${ }^{27}$ Ver: <http://www.coaf.fazenda.gov.br/menu/pld-ft/financiamento-ao-terrorismo> (com acesso em 23-09-2015).

${ }^{28}$ Ver: <http://www.coaf.fazenda.gov.br/menu/pld-ft/financiamento-ao-terrorismo> (com acesso em 23-09-2015).

${ }^{29}$ Ver as declarações de Jaime Alves de Freitas, ex-secretário-executivo do COAF: "Caso \& Caso: 1 a coletânea de casos brasileiros de lavagem de dinheiro": "Posteriormente, ao final de 2003, ocorreu a integração entre os sistemas do COAF [SISCOAF] e do Banco Central (Sisbacen), permitindo que todas as informações fossem registradas e disponibilizadas de forma eletrônica. Implementou-se, também, a figura do dossiê virtual, que permite a inserção de documentos, informações, imagens e análises procedidas, diretamente no sistema COAF, eliminando-se a necessidade de arquivos físicos para guarda de processos que, além de permitir maior agilidade e facilidade de localização das informações, com reflexos positivos diretos no resultado dos trabalhos afetos ao COAF, ampliou o controle no acesso aos dados sigilosos por parte de pessoas não autorizadas”, p.21.

${ }^{30}$ Ver entrevista com Adrienne Senna Jobim, primeira presidente do COAF (1998-2002), em "Caso \& Caso: 1ª coletânea de casos brasileiros de lavagem de dinheiro", p.10-11.

${ }^{31}$ Ver as declarações de Jaime Alves de Freitas, ex-secretário-executivo do COAF: "Caso \& Caso: 1ª coletânea de casos brasileiros de lavagem de dinheiro", p.22.

${ }^{32}$ Ver: <http://www.coaffazenda.gov.br/menu/a-inteligencia-financeira/recebimento-e-analise-de-comunicacoes> (com acesso em 23-09-2015).

${ }^{33}$ Ver: <http://www.coaffazenda.gov.br/menu/a-inteligencia-financeira/recebimento-e-analise-de-comunicacoes> (com acesso em 23-09-2015).

${ }^{34}$ Ver: <http://www.coaf.fazenda.gov.br/menu/a-inteligencia-financeira/relatorio-de-inteligencia-financeira-rif> (com acesso em 23-09-2015).
} 
Recebido o RIF pela autoridade competente, passa o sigilo a ser responsabilidade desta. ${ }^{35}$

Com relação ao intercâmbio de informações (compartilhamento do RIF) pela solicitação de outro órgão (nacional ou estrangeiro), é necessário o cumprimento dos seguintes requisitos: (a) que a autoridade solicitante seja responsável pelo procedimento de investigação do crime de lavagem de dinheiro (ou de qualquer outro ilícito objeto do pedido); (b) que na solicitação estejam: o número e a natureza do procedimento de investigação instaurado, informações sobre os fundados indícios da existência do ilícito sob investigação (com indicação do respectivo tipo penal) e identificação das pessoas envolvidas na investigação (indicando o nome e o CPF ou CNPJ). ${ }^{36}$

Diante das exigências internacionais e do perfil de atuação do COAF, que possui (com base no Dec. n.7.482/11, anexo II) 30 funcionários, sendo 15 destes responsáveis pela análise e fiscalização das comunicações de operações suspeitas, fica evidente tratar-se de órgão que necessita de grande suporte financeiro, tecnológico e de pessoal, ou, de outro modo, corre o risco de não ter sua atuação ocorrendo de forma eficaz.

Para além disso, em face do exposto, resta claro que a tutela da informação é bastante rígida no ordenamento jurídico brasileiro em matéria de combate à lavagem de dinheiro e passa diretamente pelo controle que os entes reguladores fazem dessa mesma informação. Resta saber, enfim, até que ponto a tutela da informação tem ajudado os reguladores da atividade financeira a atingirem seus objetivos de forma eficiente, ou se, de forma contrária, tem levado estes mesmos entes à captura pelos agentes regulados em função (I) da dependência que teriam dos regulados na prestação das informações e (II) da disfunção no exercício das atividades causada pelo excesso de informações a processar. Antes de se concluir de uma forma ou de outra, passa-se a seguir a detalhar um pouco mais a teoria da captura das agências reguladoras.

\section{TEORIA DA CAPTURA}

Diante da relevância do papel desempenhado pelas agências reguladoras, é natural que exista uma intensa pressão por parte dos setores regulados para que seus interesses sejam atendidos. É inegável, contudo, reconhecer que a defesa apaixonada de um modelo de agências independentes pode carregar, no mínimo, uma forte carga de ingenuidade. Também, sonhar com autoridades equilibradas, imparciais e tecnicamente preparadas, democráticas e comprometidas com o interesse público pode passar longe da realidade. ${ }^{37}$

Por essa razão, cunhou-se, a partir da década de 1960, a expressão "captura", quando relacionada à

\footnotetext{
${ }^{35}$ Ver: <http://www.coaf.fazenda.gov.br/menu/a-inteligencia-financeira/relatorio-de-inteligencia-financeira-rif > (com acesso em 23-09-2015).

${ }^{36}$ Ver: <http://www.coaf.fazenda.gov.br/menu/a-inteligencia-financeira/intercambio-de-informacoes> (com acesso em 23-092015).
} 
influência desmedida e perniciosa das empresas integrantes do mercado regulado sobre os entes reguladores responsáveis pela sua fiscalização. A "captura" de uma agência leva, ao seu final, a uma situação em que os responsáveis pela gestão da agência tornam-se representantes dos interesses do setor regulado, configurando uma face do desvio de finalidade.

Duas teorias desenvolvidas por George J. Stigler explicam esse fenômeno, conforme Justen Filho ${ }^{38}$. Primeiro, (1) a teoria do ciclo de existência das agências reguladoras descreve que existe um período em que o ente regulador atua efetivamente, livre das influências externas dos setores regulados, sendo este período seu início. Com o passar do tempo, a agência começa a depender de informações dos controlados, os quais adquirem papel cada vez mais relevante na determinação das políticas desenvolvidas pela agência. De acordo com a segunda teoria, (2) a teoria econômica da captura, aponta a regulação tão somente para atender aos interesses dos regulados, ou seja, a própria regulação surgiria já infectada pelos interesses do setor regulamentado. Isso faria com que, a longo prazo, aqueles agentes que conseguem adaptar-se de forma mais eficaz à regulação passem a descumpri-la ou somente cumpri-la de modo parcial e economicamente intencional e direcionado, assim valendo-se da regulação e da agência reguladora para ganharem vantagem concorrencial em relação aos demais agentes de mercado, que têm seus custos de transação aumentados. Em última instância, estariam capturando as agências para causar distorções na concorrência às custas de toda a coletividade (usuários do serviço público que terminam tendo um serviço mais caro e que ainda assim não cumprem a regulação). $\mathrm{O}$ traço comum a ambas as teorias pode ser traduzido como a prevalência da influência dos setores regulados em detrimento da participação democrática.

O baixo desempenho das agências reguladoras no Brasil sinaliza para a ocorrência desse fenômeno, cujos desvios em favor do regulado se apresentam, na maioria das vezes, de forma sutil, aproveitando-se das brechas das próprias normas reguladoras.

Em que pese que a teoria da captura é largamente utilizada para exigir a desregulamentação da economia fundamentada pela comprovação de que a regulamentação está sendo utilizada por agentes do mercado para causar distorções na concorrência e aumento de custos para toda a coletividade, parte-se aqui do pressuposto de que, se a regulamentação existe, ela só existe porque sua ausência em algum momento era considerada igualmente danosa para a coletividade. Deste modo, de forma a compensar os danos da regulação e mantê-la, é preciso identificar quando existe captura e por que isto ocorre.

É com base nestas premissas que se passa, a seguir, à análise crítica do sistema brasileiro de combate à lavagem de dinheiro, buscando (1) apontar se há ou não captura dos entes reguladores do sistema financeiro na

\footnotetext{
${ }^{37}$ SUNDFELD, Carlos Ari. Introdução às agências reguladoras. In: Direito administrativo econômico. São Paulo: Malheiros, 2000. p.73.

${ }^{38}$ JUSTEN FILHO, Marçal. O direito das agências reguladoras independentes. São Paulo: Dialética. 2002.
} 
matéria e, se existente, (2) apontar por que isso acontece e (3) quais as possíveis medidas que podem mitigar o problema.

\section{APONTAMENTOS CRÍTICOS AO SISTEMA BRASILEIRO DE COMBATE A LAVAGEM DE DINHEIRO: A POSSIBILIDADE DE CAPTURA DAS AGÊNCIAS}

Como já demonstrado acima, algumas das principais atividades de BACEN e COAF se relacionam justamente com o processamento das informações prestadas pelos agentes privados. Em especial, cabe levantar a relevância dos RIFs produzidos pelo COAF, visto que são cruciais no processamento e na análise das operações comunicadas. Por apontarem as operações com suspeita de lavagem de dinheiro, esses relatórios terminam por condicionar e direcionar a quantidade de inquéritos e, consequentemente, ações penais e condenações em lavagem de dinheiro no País, sendo elementos centrais do sistema de controle.

Resta, então, saber se este tipo de regulação é eficaz frente ao que pretende enfrentar. Neste sentido, analisando-se historicamente, observa-se que, no início, houve alto crescimento de inquéritos, ações penais e condenações em lavagem de dinheiro, em especial no período de 2003 a 2006, quando foi maior a informatização e a integração entre as instituições envolvidas no combate a este delito, com especial destaque para a atuação do COAF, sozinho e em parceria com a Polícia Federal. ${ }^{39}$

Quanto ao BACEN, vale ressaltar sua eficiência na exigência das informações precisas de seus regulados, bem como na análise de informações antes do repasse ao COAF, no período inicial de atuação no controle contra a lavagem. De acordo com as estatísticas disponibilizadas pelo COAF, em 2009, foram comunicadas 93.270 operações suspeitas pelos setores regulamentados pelo BACEN, com o nível de acertos (\% útil das informações prestadas) apurado após a denúncia e a emissão do relatório de inteligência financeira, girando em torno de $57 \%$.

Restaria saber, então, se o controle aumentou em número de operações e em eficiência ao longo dos anos. Para isto, necessário se faz analisar alguns dados de especial importância para este trabalho.

De início, importante é observar os números de comunicações recebidas dos setores obrigados entre os anos de 2011 e $2014^{41}$, assim incluindo os últimos quatro anos de dados consolidados, dois antes e dois após a

\footnotetext{
${ }^{39}$ MANZI, Vanessa Alessi. Compliance no Brasil: Consolidação e perspectivas. São Paulo. Editora Saint Paul, 2008, p. $57-59$.

${ }^{40}$ COIMBRA, Marcelo de Aguiar; MANZI, Vanessa Alessi (Org). Manual de compliance. Preservando a boa governança e a integridade das organizações. São Paulo: Editora Atlas, 2010, p.72.

41 Dentre os números de 2012 a 2014, há divergências no próprio site do COAF, onde no disponível em: <http://www.coaffazendagov.br/dados-abertos/coaf-em-numerosxls/@@download/file/COAF\%20em\%20numerosxls> há inversão entre os números de 2012 e 2014. Deduz-se que este arquivo inverteu os dados, porque no arquivo disponível em: <http://www.coaf.fazenda.gov.br/dados-abertos/comunicacoes-por-segmento-anosanteriores.xls/@@download/file/C\%C3\%B3pia\%20de\%20Comunica\%C3\%A7\%C3\%B5es\%20por\%20Segmento\%20\%20anos\%20anteriores.xls>, há o número apontado de 1.587 .427 para 2012 e 1.144 .452 para 2014, sendo que, neste último arquivo, os números citados configuram a soma das comunicações de todos os segmentos, enquanto o primeiro só dá os números sem apontar do que eles se compõem, dando a entender que houve mera confusão de digitação antes de colocar os números
} 
efetivação da nova redação da Lei Antilavagem. Neste sentido, as operações suspeitas foram: em 201 1, 1.289.087; em 2012, 1.587.427; em 2013, 1.286.233; em 2014, 1.144.542.

Percebe-se que há um número muito alto de operações comunicadas, sempre ultrapassando um milhão. Vale ressaltar que, dentro das operações em espécie acima elencadas, a maior parte delas é prestada justamente pelo BACEN, que representa sempre mais da metade das comunicações, com valores sempre crescendo. Desta forma, os relatórios do COAF servem para demonstrar que o BACEN é o maior responsável pelas informações prestadas; logo, protagonista do sistema financeiro e do controle antilavagem.

Quanto às operações classificadas como atípicas, que atraem maiores atenções dos entes reguladores por conterem indícios mínimos de prática de lavagem, os números seguem caminho aparentemente inverso, a ver ${ }^{42}$ :

Em 2011, elas eram 559.992, sendo 37.237 do BACEN e 16.684 do COAF; em 2012, elas foram 775.535, sendo 41.819 do BACEN e 55.646 do COAF; já em 2013, 426.153 no total, sendo 53.244 do BACEN e 62.732 COAF; enfim, em 2014, eram 177.467 operações suspeitas para 57.455 do BACEN e 53.818 do COAF. Em números absolutos, graficamente:

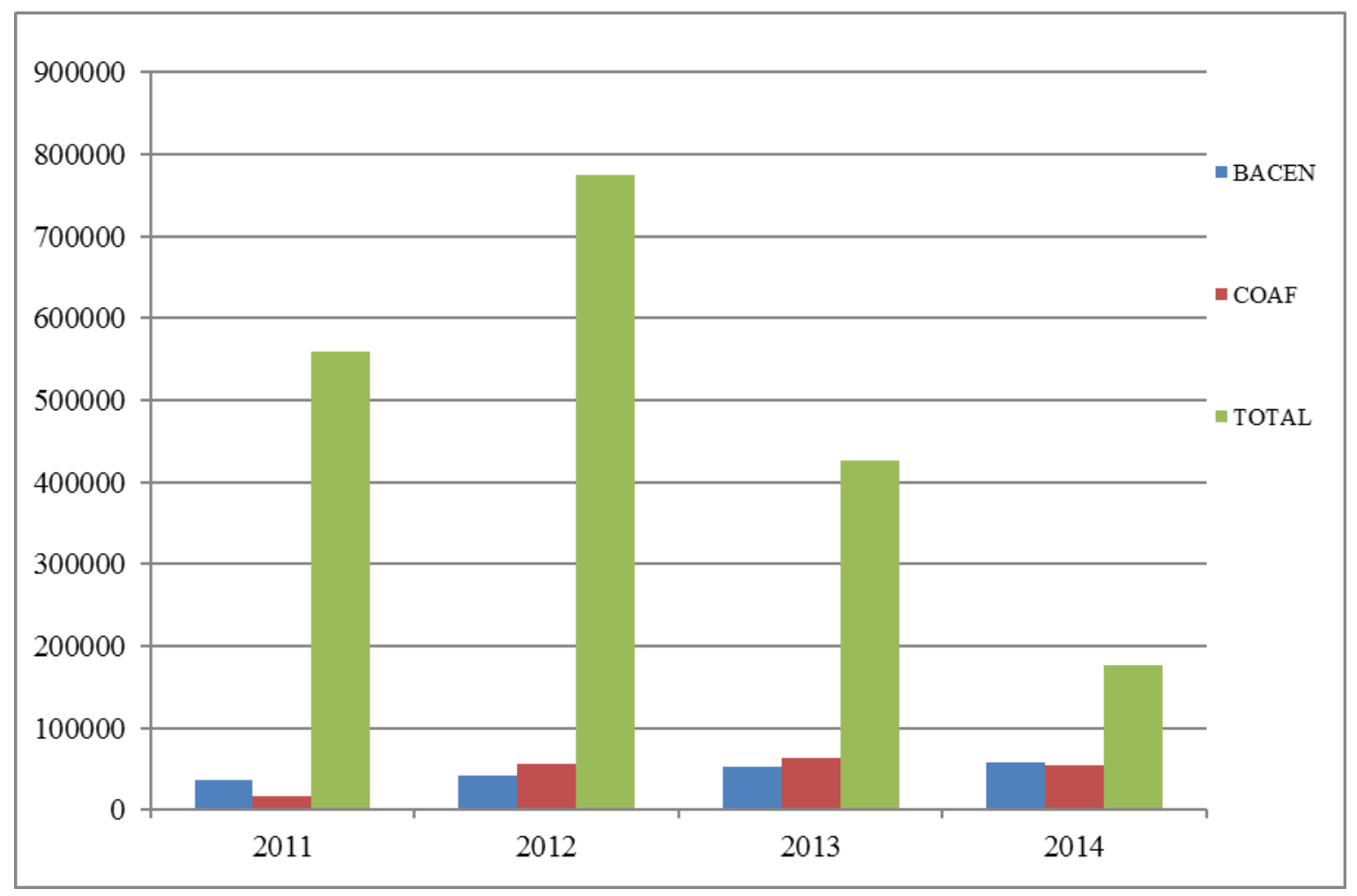

naquele arquivo específico. Em tentativa de contato oficial para esclarecimento, não obtivemos resposta, de modo que adotaremos a interpretação aqui explicada, tanto por ser mais lógica, quanto porque a inversão não faz tanta diferença para o objeto e as conclusões deste trabalho. Ambos os arquivos foram acessados entre setembro e dezembro de 2015.

$42 \quad$ Disponível em: <http://www.coaf.fazenda.gov.br/dados-abertos/comunicacoes-por-segmento-anosanteriores.xls/@@download/file/C\%C3\%B3pia\%20de\%20Comunica\%C3\%A7\%C3\%B5es\%20por\%20Segmento\%20\%20anos\%20anteriores.xls> (com acesso continuado em set.-dez., 2015). 
Observa-se, a partir do gráfico, que o caminho seguido pelas operações suspeitas, no total, parece apontar para o decréscimo. Resta então apontar para as causas de isso acontecer dessa forma, o que é possível apurar nos mesmos arquivos do COAF. De fato, a diminuição em 2013 e 2014 pode ser referente a uma correção de distorção por excesso de exigência da regulação. Antes deste período, Loterias e Mercado Segurador estavam informando operações suspeitas em grande quantidade (Loterias na casa dos 150 a 200 mil e Mercado Segurador na casa dos 300 a 500 mil) e baixíssima efetividade (0,59\% para Loterias e 1,33\% para Mercado Segurador). Com a normalização das comunicações prestadas por eles (na casa de 4.500 para Loterias e 45 mil para Mercado Segurador em 2014, números bem abaixo dos anteriores), a quantidade de operações suspeitas terminou diminuindo em proporção inversa ao aumento da prestação de informações dos demais setores. Esta mesma correção pode justificar, ainda, a queda de todas as comunicações recebidas a partir de 2012.

Para corroborar este apontamento, os setores de maior interesse para este trabalho, COAF e BACEN, fizeram exatamente o caminho inverso das operações suspeitas no total, apontando para acréscimo no período.

E se as comunicações suspeitas despencaram, a proporção de operações suspeitas dentro das operações comunicadas no total, igualmente despenca, chegando ao número de 177.467 operações atípicas para 1.144.542 comunicações totais no ano de 2014, configurando quase um milhão de comunicações não aproveitadas que ficaram somente armazenadas como dados.

Cabe ressaltar, por outro lado, que ao contrário do número total, os números de operações suspeitas oriundas dos setores de interesse deste trabalho, BACEN e COAF, aumentaram, contudo em proporções bastante diferentes. No caso do COAF, o aumento no período justifica-se também pela alteração legislativa, uma vez que muitos setores sem órgão regulador passaram a ser obrigados e se reportaram justamente a ele, COAF; mas em 2014, a diminuição aponta para uma possível "normalização" no período a seguir. Por outro lado, no caso do BACEN, ao contrário do COAF, não houve aumento brusco no número de comunicações de atividades suspeitas, seguindo uma linha de aumento constante e regular das comunicações totais.

Contudo, de maior interesse aqui é a única variável que se apresenta comum a todos os setores sujeitos à tutela da informação no sistema financeiro (tanto os dois entes de maior interesse para este trabalho quanto os demais): a discrepância entre total informado e operações atípicas, sempre diminuindo, aos poucos, a proporção de comunicações de operações suspeitas frente às comunicações de operações em geral prestadas pelos segmentos, isoladamente. Assim, independentemente de um setor comunicar mais ou menos operações suspeitas a cada ano, este mesmo setor estará sempre comunicando proporcionalmente menos operações suspeitas no mesmo período.

E se a análise das comunicações totais, em comparação com as operações suspeitas, já aponta para uma preocupante sobrecarga do COAF com informações com pouca utilidade que aumentam a cada ano, quando 
observado o grau de eficiência, que, como já afirmado, era de 57\% para os regulados pelo BACEN em 2009, as preocupações acentuam-se. Isto porque a eficiência no período esteve em $25,31 \%$ para o COAF e somente $15,92 \%$ por parte do BACEN, o que demonstra absoluta queda na eficiência das informações prestadas pela autarquia.

Somando os dois fatores acima expostos, quais sejam (1) a diminuição na proporção de comunicações de operações suspeitas frente às comunicações de operações em geral, e (2) a absoluta queda na eficiência das informações prestadas, é possível concluir que o aumento de controle em operações acima de certo valor só tem servido para aumentar o banco de dados e, de certo modo, sobrecarregar o COAF, além de criar ilusão sobre controle, e descontrolar o que vem abaixo, pois, uma vez que o ente regulado sabe que só serão avaliadas as operações que ele indica como suspeitas, porque são muitas as operações comunicadas, então ele tem o controle sobre o que o regulador irá apurar de fato: somente as operações que ele indicar como suspeitas.

Em face disso, um agente regulado, valendo-se da dependência do ente regulador e da quase certa impossibilidade de ser descoberto, pode tanto falsificar como esconder informações essenciais em casos de lavagem, bem como propositadamente comunicar várias operações que sabe serem lícitas como se fossem operações suspeitas, de modo a sobrecarregar de informações - e assim aumentar a dependência - do regulador. Como caso prático em que isso aconteceu, é possível citar a Ação Penal 470/MG, onde o réu Henrique Pizzolato teve sua condenação por lavagem de dinheiro fundamentada, dentre outros motivos, por ter falsificado dados e omitido comunicações ao COAF durante o acontecimento do chamado "Mensalão" para garantir que os proveitos ilícitos fossem mascarados no sistema financeiro. Esta conduta nunca foi apurada pelo órgão regulador, sendo que só pôde ser descoberta após o desenrolar da sobredita Ação Penal e a conferência das provas documentais e testemunhais, contrariando o conteúdo das comunicações falsamente prestadas.

Inclusive, nada impede que isto continue acontecendo, pois, se o órgão não consegue sequer apurar todas as comunicações fornecidas, que é sua função primária, dificilmente conseguirá apurar, dentre as comunicações de operações suspeitas que não apresentaram reais indícios de lavagem, quais foram prestadas dolosamente inúteis para sobrecarregar o COAF. Ainda, se aquelas operações que são suspeitas ou certas de que se tratam de lavagem de dinheiro, mas contaram com uma comunicação falsa de que se tratam de operações comuns, já são de difícil descoberta, menos provável ainda que os órgãos de controle consigam apurar os casos de lavagem de dinheiro quando ocorrerem em operações que não estejam dentre as obrigatoriamente comunicáveis no âmbito da Lei 9.613/98 e a regulação derivada (por exemplo, as operações abaixo de 100 mil reais que um programa de compliance efetivo e seguidor da regulamentação vigente não consiga, ainda assim, encontrar e apontar como suspeita).

Esta dependência que COAF e BACEN apresentam em relação a seus regulados na matéria de lavagem 
de dinheiro aponta para a captura das agências, sendo que esta é consequência da assimetria de informações que permeiam o sistema desde o início.

A seguir, para corroborar esta tese, uma tabela sobre as atividades realizadas pelo COAF entre $2012 \mathrm{e}$ 2014:

\begin{tabular}{|l|c|c|c|c|c|}
\hline \multicolumn{5}{|c|}{ TODAS AS ATIVIDADES REALIZADAS PELO COAF ENTRE 2012 E 2014 } \\
\hline & 2012 & 2013 & 2014 & Total \\
\hline Comunicações recebidas dos setores obrigados & 1.587 .427 & 1.286 .233 & 1.144 .542 & 4.018 .202 \\
\hline Relatórios de Inteligência Financeira (RIF) produzidos & 3.178 & 2.450 & 2.104 & 7.732 \\
\hline Comunicações relacionadas nos RIFs & 105.259 & 108.962 & 85.759 & 299.980 \\
\hline Pessoas relacionadas nos RIFs & 77.049 & 52.812 & 15.772 & 145.633 \\
\hline Intercâmbio com autoridades nacionais & 2.971 & 3.107 & 2.421 & 8.499 \\
\hline Intercâmbio realizado com UIF (Rede de Egmont) & 160 & 170 & 164 & 494 \\
\hline Bloqueio de recursos (em R\$ milhões) & 484 & 927,5 & 61,4 & 1.473 \\
\hline Averiguações Preliminares concluídas & 73 & 27 & 16 & 116 \\
\hline Cadastramento de pessoas reguladas & 1.748 & 2.685 & 771 & 5.204 \\
\hline Processo Administrativo Punitivo instaurados & 45 & 9 & 6 & 60 \\
\hline Processo Administrativo Punitivo julgado & 12 & 10 & 18 & 40 \\
\hline Advertências aplicadas & 21 & 17 & 18 & 56 \\
\hline Multas aplicadas (em R\$ mil) & 211,1 & 624,4 & 453,2 & 1.289 \\
\hline
\end{tabular}

De relevante, observa-se que alguns valores aumentam do primeiro ano para o segundo e caem drasticamente do segundo para o terceiro, demonstrando queda na comparação entre 2012 e 2014, casos de: (a) Comunicações relacionadas nos RIFs, (b) Bloqueio de recursos (em R\$ milhões) e (c) Cadastramento de pessoas reguladas. Com exceção do bloqueio recursos, que parece ser instável e dependente das grandes operações, os demais apontam para queda no apurado, apesar das variações.

Observando ainda no comparativo entre 2012 e 2014, somente as multas aplicadas demonstram aumento relevante, enquanto o intercâmbio com demais UIFs (Rede Egmont) mantém-se constante, com aumento bem pequeno. Já os demais dados apontam todos para a queda nas atividades do COAF, sendo especialmente relevante a diminuição nos Relatórios de Inteligência Financeira (RIF) produzidos, nas Pessoas relacionadas nos RIFs e nos Processos Administrativos Punitivos instaurados, com isto tudo ocorrendo em um período de mudança legislativa que visou ao endurecimento dos deveres por parte dos particulares e ao aumento da tutela da informação.

Finalmente, a soma dos dados e das reflexões acima expostos termina apontando para a captura do COAF e demonstrando a ineficiência preventiva e sancionatória do sistema de controle de lavagem de dinheiro do Brasil.

O resultado disso, na prática, somente no ano de 2014, foi: 1.144 .542 operações comunicadas (967.056 
do BACEN); para 177.467 operações atípicas (57.455 BACEN e 53.818 COAF, com aproximadamente 16\% e 25\% de precisão, respectivamente); formando 2.104 RIFs com 15.772 pessoas envolvidas; para culminar, em 16 averiguações preliminares concluídas, 6 Processos Administrativos instaurados, 18 julgados com 18 advertências aplicadas e 453 mil reais em multas. É um sistema que, além de caro, é deficitário e ineficaz. A tentativa de compensar isso com o aumento de multas somente constrange as autoridades, visto tratar-se de valores pequenos para os sancionados e justamente na modalidade sancionatória que os regulados melhor absorvem. Sanções pecuniárias tímidas para agentes financeiros não parecem ser exatamente medidas dissuasórias muito inteligentes.

Assim, é possível apontar a captura de COAF e BACEN na regulação contra a lavagem de dinheiro sob a perspectiva de ambas as teorias:

Desde a perspectiva do (1) ciclo de vida das agências, o COAF enquadrou-se exatamente na moldura de ter uma atividade inicial muito profícua, passar a depender das informações do ente regulado em momento posterior e terminar, hoje, defendendo os interesses dos regulados, na medida em que lhes garante altos padrões de "cumprimento normativo" ao dar garantia de que cumpriram a legislação antilavagem, o que é impossível de apurar se é verdadeiro ou não. Terminam, enfim, por legitimar as atividades eivadas de ilegalidades do sistema ao promover uma regulação de impactos quase nulos na realidade.

Já sob a perspectiva da (2) teoria econômica, o fato de a lei já ter sido feita de modo a manter a assimetria de informações entre agentes reguladores e particulares aponta que a lei mesma foi feita já no interesse das corporações em regras do jogo que elas mesmas propuseram e aceitaram ${ }^{43}$. A própria Lei cria uma margem de dependência sem solução que as agências reguladoras têm de seus entes regulados ao prever a necessidade da prestação de informações nestes volumes e limites. A partir disso, há regulados que são mais fortes, adaptam-se melhor à regulação e têm ganhos nos custos de transação, repassando a todos os custos da regulação de modo a se beneficiarem ${ }^{44}$. Neste sentido, é possível citar, como exemplo, o caso do HSBC Holdings PLC citado na introdução e as evasões de divisas para a Suíça, em que o referido banco terminava por ter vantagens na captação de vários clientes de alta renda (que desejavam ter ativos depositados em paraísos fiscais), justamente por não cumprir a regulação. A adaptação à regulação terminou por fazer com que, para existir o benefício do banco e de seus clientes por muito tempo, toda a sociedade arcasse com os custos, seja no caso da deslealdade na concorrência que onerava os outros bancos, seja no caso de prejuízo para os clientes não beneficiários das irregularidades, que pagavam por um custo de transação que, na realidade, estava bem abaixo, assim como no prejuízo difuso para a sociedade, que arcou com as evasões de divisas, sonegações fiscais e outras possíveis origens ilícitas dos ativos que atentaram contra o patrimônio público e a economia nacional.

\footnotetext{
${ }^{43}$ Em especial, observar como muitas das disposições antilavagem advêm do Comitê de Basileia.

${ }^{44}$ SZTAJN, Rachel. Teoria Jurídica da empresa: atividade empresária e mercados. São Paulo: Atlas, 2004. p.54.
} 
E sendo possível falar em captura aqui, os motivos para ela parecem ser inicialmente três (3): (1) falta de estrutura dos órgãos de controle, em especial o COAF; (2) legislação que já privilegia e mantém a assimetria de informações, tornando entes reguladores dependentes dos entes regulados; (3) necessidade de evolução tecnológica para acompanhar os avanços do sistema financeiro.

Quanto à (1) falta de estrutura dos órgãos de controle, "apesar da relevância da atividade de sistematização de informações, os números apresentados pelo COAF demonstram a carência de estrutura do órgão. Embora contem com quadros de técnicos bem treinados, não existem servidores em número suficiente para processar e analisar toda a informação recebida" ${ }^{\prime 4}$, sendo isto evidenciado pelo fato de serem destinadas 15 , dentro de um grupo máximo de 30 pessoas, para processar mais de um milhão de comunicações a cada ano. E para além, "os poucos relatórios encaminhados não resultam em investigações efetivas, também pela falta de quadros e de estruturas de outras instituições, como a Polícia Federal. De dois mil Relatórios de Inteligência Financeira encaminhados pelo COAF à Polícia Federal de 2005 a 2010, apenas 136 inquéritos policiais foram gerados" ${ }^{46}$ A desproporção entre os números demonstra a ineficácia do sistema e a necessidade de ampliação dos quadros e da estrutura dos órgãos de controle.

No que se refere à (2) Legislação que já privilegia e mantém a assimetria de informações, tornando entes reguladores dependentes dos entes regulados, é possível citar que as operações abaixo de 100 mil reais não estão no "radar" das autoridades, exceto em casos de comunicações dos entes regulados, o que faz com que o ente regulador só possa saber de operações ilícitas abaixo de 100 mil reais (mesmo quando forem, por exemplo, várias de 90 mil que completem valores totais muito superiores) se contar com ajuda e denunciação das instituições financeiras por onde esse dinheiro passou ${ }^{47}$.

Ainda, mesmo no caso das operações acima deste valor, ainda que haja seu controle e armazenamento, nada impede que uma operação ilícita passe despercebida porque os órgãos reguladores se preocupam mais com aquilo que os entes regulados já avisam ser uma operação atípica em função do excesso de operações informadas.

Além do mais, ainda que uma comunicação falsa possa gerar sanções, isso só ocorre quando comprovada sua "má-fé", algo que sequer tem como ser amplamente averiguado pela mesma impossibilidade material em face do excesso de trabalho a ser feito pelos agentes do COAF. Nada impede que o sistema de informações seja supersaturado de comunicações de operações irrelevantes para o controle da lavagem de ativos, deste modo escondendo as operações que se deseja coibir.

\footnotetext{
45 BADARÓ, Gustavo Henrique; BOTTINI, Pierpaolo Cruz. Lavagem de Dinheiro: aspectos penais e processuais penais: comentarios à Lei 9.613 com as alterações da Lei 12.683/2012. São Paulo: Editora Revista dos Tribunais, 2013, p.44.

${ }^{46} \mathrm{Ibid}$.

${ }^{47}$ Uma das funções de compliance é, inclusive, apurar esse tipo de conduta de "fracionar" uma grande transação em várias transações menores. Somente a partir da apuração da situação pelo agente privado é que a denúncia é feita ao poder público para passar por seus vários filtros até uma possível condenação em matéria de lavagem de dinheiro.
} 
Enfim, no que tange à (3) necessidade de evolução tecnológica para acompanhar os avanços do sistema financeiro, é sabido que este é altamente informatizado, moderno e tecnológico, motivo pelo qual o controle da lavagem de ativos tem sido extremamente difícil e caro historicamente. Se o déficit tecnológico dos entes controladores se mantiver, as ações são inócuas. De fato, a tecnologia e a internet têm transformado cada vez mais o sistema financeiro. ${ }^{48}$ A perseguição à lavagem de dinheiro, "assim como nasce de mãos dadas com a guerra contra as drogas, pelo momento, outorga um pequeno prognóstico desalentador quanto a seu inevitável fracasso, da mesma forma que a política antinarcóticos" ${ }^{49}$ A única alternativa que se apresenta para minimizar os danos e tentar antecipar-se ao poder econômico e tecnológico das organizações criminosas é, em vez de ampliar os obrigados e seus deveres na Lei Antilavagem, informatizar programas de prevenção e a atividade estatal na esfera da autorregulação regulada, conseguindo maior efetividade mesmo com recursos e pessoal limitados e sem ampliar os deveres - e responsabilidades - dos particulares, em especial aqueles com repercussão penal incidindo na própria esfera da liberdade dos sujeitos. Neste sentido, algumas soluções já se têm apresentado mundo afora ${ }^{50}$.

\section{CONCLUSÕES}

O contexto da "autorregulação regulada" para evitar a lavagem de dinheiro parece inevitável, uma vez que o próprio Estado assume ser incapaz de controlar o sistema financeiro sem a ajuda dos particulares. Contudo, ainda que compliance (a pedra angular do sistema) possa ser útil na prevenção de condutas indesejadas, não pode ser tratado como uma solução definitiva para a problemática, uma vez que sequer está provada sua efetividade ${ }^{51}$, ainda mais no sistema antilavagem brasileiro, onde, ao contrário, os indícios de sua ineficiência preventiva e de sua contribuição para a captura das agências reguladoras parecem ser bastante robustos.

Diante do contexto, é possível supor com algum grau de precisão estar ocorrendo o chamado fenômeno da captura, tanto do BACEN quanto do COAF, no controle dos entes regulados em matéria de lavagem de ativos.

A partir disso, se não forem resolvidos os 3 problemas da (1) falta de estrutura dos órgãos de controle,

\footnotetext{
${ }^{48}$ DAVIN, João. O branqueamento de capitais - breves notas (o caso português). In: OLIVEIRA, William Terra de; LEITE NETO, Pedro Ferreira; ESSADO, Tiago Cintra; SAAD-DINIZ, Eduardo (coord.). Direito penal econômico: estudos em homenagem aos 75 anos do professor Klaus Tiedemann. São Paulo, SP: LiberArts, 2013, p. 218.

${ }^{49}$ SABADINI, Patrício Nicolás. Avanços e retrocessos em matéria de lavagem de dinheiro. A perspectiva argentina. In: OLIVEIRA, William Terra de; LEITE NETO, Pedro Ferreira; ESSADO, Tiago Cintra; SAAD-DINIZ, Eduardo (coord.). Direito penal econômico: estudos em homenagem aos 75 anos do professor Klaus Tiedemann. São Paulo, SP: LiberArts, 2013, p. 245.

${ }^{50}$ Digna de nota é a solução de compliance da SAS para combate a fraudes e lavagem de dinheiro. O modelo utiliza programas de computador que processam os dados oriundos dos deveres de compliance e assim detectam, investigam e relatam potenciais atividades ilícitas com a incorporação de análises de alto desempenho, compatíveis com o chamado Big Data. Matéria completa em: $\quad<$ http://corporate.canaltech.com.br/noticia/seguranca/Solucao-SAS-contra-lavagem-de-dinheiro-e-premiada-por-revistabritanica/\#ixzz3JBGjZ7Zx> (Canaltech. Solução SAS contra lavagem de dinheiro é premiada por revista britânica, com acesso em 05-06-2014). Soluções como essa apontam para o futuro do combate à lavagem de dinheiro, inserindo-se na esfera da tecnologia da informação em parceria com o direito.
} 
(2) da brecha legislativa que privilegia a assimetria de informações e (3) da necessidade de evolução tecnológica para acompanhar os avanços do sistema financeiro, o discurso contra a lavagem de ativos será meramente ilusório.

Por isso é que se fala na hipótese da mera transferência de responsabilidades: o que antes era função do Estado passa a ser, agora, dever dos entes privados (encontrar operações suspeitas). E se a criação desses deveres se justificava minimamente pela tentativa de proteção de determinados interesses do Estado (combater a lavagem), questiona-se até onde se trata realmente de um interesse do Estado se ele, em nada, tem aparelhado os órgãos que vão averiguar as informações provenientes do cumprimento desses deveres que, muitas vezes, podem

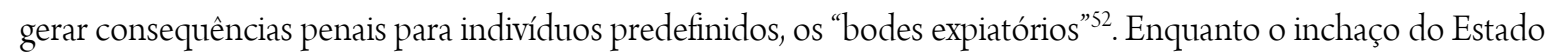
policial militar para o combate violento e ineficaz do crime organizado da chamada criminalidade de ruas aumenta a cada dia, não é visto o mesmo empenho para cortar aquilo que sustenta e fortalece o crime organizado, não só aquele, mas, sim, todo ele, incluindo a criminalidade do colarinho branco: o dinheiro.

\title{
THE “ENFORCED SELF-REGULATION" MODEL AND THE THEORY OF CAPTURE: OBSTACLES TO THE EFFECTIVENESS IN MONEY LAUNDERING COMBAT IN BRAZIL
}

\begin{abstract}
This article aims to point out how the "enforced self-regulation" system in the fight against money laundering in Brazil, by means of compliance incentive, leads to the so-called phenomenon of the regulatory agencies' capture, avoiding that the prevention and the fight against the referred crime are really effective. To achieve it, the structure of the prevention and fighting this crime system was described, with special attention to the enforced selfregulation and the duties imposed to private agents of prevention by means of compliance and informing to the regulatory agencies with preventive goals. After that, the data from this particular structure was analyzed, finally finding out that regulatory agencies are dependent of the regulated agents, what turns the system inefficient, creating the capture of the regulators. In the conclusions, some probable causes and possible solutions to the problem are pointed.
\end{abstract}

Keywords: Money Laundering; Compliance; Enforced Self-Regulation; Capture Theory; Regulatory Agencies; Prevention and Fighting Crime; Effectiveness; Criminal Law; Public Law.

\footnotetext{
${ }^{51}$ Neste sentido, LAUFER, William S. Illusions of Compliance and Governance. In: Corporate Governance: International Journal of Business in Society, 6(3), p. 239-249, 2006.

52 Desenvolvendo a problemática e buscando reverter essa lógica perversa do sistema: ALENCAR, Matheus de. Os Programas de Compliance Como Instrumento de Proteção do Empregado na Responsabilidade Empresarial por Atos Ilícitos. 2015. Trabalho de Conclusão de Curso (Bacharel em Direito) - Faculdade de Ciências Humanas e Sociais, Universidade Estadual Paulista "Júlio de Mesquita Filho", Franca, 2015.
} 


\section{REFERENCIAS BIBLIOGRÁFICAS}

ALENCAR, Matheus de. Os Programas de Compliance Como Instrumento de Proteção do Empregado na Responsabilidade Empresarial por Atos Ilícitos. 2015. Trabalho de Conclusão de Curso (Bacharel em Direito) Faculdade de Ciências Humanas e Sociais, Universidade Estadual Paulista "Júlio de Mesquita Filho", Franca, 2015.

BADARÓ, Gustavo Henrique; BOTTINI, Pierpaolo Cruz. Lavagem de Dinheiro: aspectos penais e processuais penais: comentarios à Lei 9.613 com as alterações da Lei 12.683/2012. Prefácio de Maria Thereza Rocha de Assis Moura. São Paulo: Editora Revista dos Tribunais, 2013.

BAGATIN, Andréa Cristina. Teoria da captura: explicação necessária e suficiente para a existência de regulação? Revista de Direito Público da Economia. Belo Horizonte, ano 7, n. 28, p. 9-2, 2009.

COIMBRA, Marcelo de Aguiar; MANZI, Vanessa Alessi (Org). Manual de compliance. Preservando a boa governança e a integridade das organizações. São Paulo: Atlas, 2010.

DAVIN, João. O branqueamento de capitais - breves notas (o caso português). In: OLIVEIRA, William Terra de; LEITE NETO, Pedro Ferreira; ESSADO, Tiago Cintra; SAAD-DINIZ, Eduardo (coord.). Direito penal econômico: estudos em homenagem aos 75 anos do professor Klaus Tiedemann. São Paulo, SP: LiberArts, 2013.

JUSTEN FILHO, Marçal. O direito das agências reguladoras independentes. São Paulo: Dialética. 2002.

LAUFER, William S. Illusions of Compliance and Governance. In: Corporate Governance: International Journal of Business in Society, 6(3), p. 239-249, 2006.

Corporate Liability, Risk Shifting and the Paradox of Compliance. In: Vanderbilt Law Rewiew, vol.:52, p. 1.343-1.420, 1999

MANZI, Vanessa Alessi. Compliance no Brasil: Consolidação e perspectivas. São Paulo: Editora Saint Paul, 2008.

ROSSETTI, José Paschoal; ANDRADE, Adriana. Governança corporativa. Fundamentos, desenvolvimento e tendências. 6. ed. São Paulo: Atlas, 2012.

SAAD-DINIZ, Eduardo. O sentido normativo dos programas de compliance na AP 470. In: Revista dos Tribunais, n. 933, p. 151-165. São Paulo: Editora Revista dos Tribunais, 2013.

SAAVEDRA, Giovanni A. Reflexões iniciais sobre o controle penal dos deveres de compliance. In: Boletim IBCCRIM. São Paulo: IBCCRIM, ano 19, n. 226, p. 13-14, set., 2011.

SABADINI, Patrício Nicolás. Avanços e retrocessos em matéria de lavagem de dinheiro. A perspectiva argentina. In: OLIVEIRA, William Terra de; LEITE NETO, Pedro Ferreira; ESSADO, Tiago Cintra; SAAD-DINIZ, Eduardo (coord.). Direito penal econômico: estudos em homenagem aos 75 anos do professor Klaus Tiedemann. São Paulo, SP: LiberArts, 2013.

SCAFF, Fernando Facury; SILVEIRA, Renato de Mello Jorge. Lei Anticorrupção é substancialmente de caráter penal. ISSN 1809-2829. CONJUR, 2014. Disponível em: <http://www.conjur.com.br/2014-fev-05/renatosilveira-fernando-scaff-lei-anticorrupcao-carater-penal >, com acesso em 01-06-2014. 
SUNDFELD, Carlos Ari. Introdução às agências reguladoras. In: Direito administrativo econômico. São Paulo: Malheiros, 2000 p. 17-38. (p.370)

SZTAJN, Rachel. Teoria Jurídica da empresa: atividade empresária e mercados. São Paulo: Atlas, 2004.

Trabalho enviado em 05 de janeiro de 2017.

Aceito em 05 de janeiro de 2017. 